\title{
PAIN AT THE TIP OF THE STEM AFTER REVISION TOTAL KNEE ARTHROPLASTY
}

Rômulo Ballarin Albino', Lívia Souza Santos², Riccardo Gomes Gobbi ${ }^{3}$ Maurício lamaguchi ${ }^{3}$ Marco Kawamura Demange ${ }^{3}$, Luis Eduardo Tirico ${ }^{3}$, José Ricardo Pécora ${ }^{4}$

\section{ABSTRACT}

Objective: To correlate parameters of implants with incidence of pain. Methods: 32 knees (31 patients) operated on between 2006 to 2008 in a serie of cases of TKA revision surgery were monitored for evidence of pain at the tip of the stem.In all we used uncemented stem Scorpio TS Total Knee ${ }^{\circledR}$ Revision System (Stryker ${ }^{\circledR}$ ). Criteria assessed: pain in the leg or thigh without other causes, diameter and length of the nail; position of the rod in the medullary canal, intramedullary canal diameter. Results: Mean age was 66.7 years and mean follow-up was 2.6 years. $21,87 \%$ of patients reported leg pain, $9.37 \%$ thigh pain. The group of pacients with leg pain presented with shaft diameter $14.7 \mathrm{~mm}$, length $80 \mathrm{~mm}$ in $71.42 \%$ and $155 \mathrm{~mm}$ in $28,58 \%$, stem diameter/ intramedullary canal diameter average relation of $0,76,42.8 \%$ had stem malalignment. The group without leg pain presented with shaft diameter $15.2 \mathrm{~mm}$, length $80 \mathrm{~mm}$ in $68 \%$ and 155 $\mathrm{mm}$ in $32 \%$, diameters average relation of $0.80,20.8 \%$ had stem malalignment. The group with thigh pain presented with shaft diameter $18.3 \mathrm{~mm}$, length $80 \mathrm{~mm}$ in $66.67 \%$ and $155 \mathrm{~mm}$ in $33,33 \%$,diameters average relation of 0.75 , $0 \%$ had stem malalignment The group without thigh pain presented with shaft diameter $16.56 \mathrm{~mm}$, length $80 \mathrm{~mm}$ in $70.37 \%$ and $155 \mathrm{~mm}$ in $29,63 \%$, diameters average relation of $0.79,14,2 \%$ had stem malalignment. Conclusion: There was no association between the assessed criteria and pain in the tip of the stem.

Keywords - Arthroplasty, Replacement, Knee; Knee Joint; Pain

It has been noted that, after primary and revision arthroplasty, some patients persist with pain after the surgery. Even after investigation with physical examinations, imaging examinations and laboratory tests in an attempt to find a triggering factor such as poor positioning, loosening, instability and inflammatory or infectious causes, many cases of pain remain without defined etiology. Pain located in the diaphyseal portion of the femur and tibia has been correlated with the presence of the nail in revision arthroplasty ${ }^{(4,5)}$. Likewise, pain in the thigh has been correlated with hip arthroplasty, and variations in the material, design, size and module of elasticity have been regarded as possible associated factors ${ }^{(6-9)}$.

1 - Resident Physicians of the Institute of Orthopedics and Traumatology, HC/FMUSP.

2 - Resident Physicians of the Institute of Orthopedics and Traumatology, HC/FMUSP.

3 - Assistant Physicians of the Institute of Orthopedics and Traumatology, HC/FMUSP.

4 - Assistant Physician and Head of the Knee Group of the Institute of Orthopedics and Traumatology, HC/FMUSP.

Work carried out at the LIM 41 - Medical Investigation Laboratory of the Musculoskeletal system of the Department of Orthopedics and Traumatology, Faculty of Medicine, Universidade de São Paulo

Correspondence: Rua Dr. Ovídio Pires de Campos, 333 Cerqueira César, CEP.: 05403-010 - E-mail: romulo.albino@gmail.com Received for publication: 05/31/2011, accepted for publication: 07/26/2011

The authors declare that there was no conflict of interest in conducting this work 
The objectives of this study were to analyze the incidence of pain at the nail tip in patients who underwent knee arthroplasty revision at our service between 2006 and 2008 and to investigate a possible relationship between pain at the nail tip and the percentage filling of the medullary canal or nail length.

\section{MATERIALS AND METHODS}

We followed up 31 patients who underwent TKA revision surgery between 2006 and 2008, who were evaluated prospectively regarding occurrences of lower-leg and thigh pain that possibly resulted from the intramedullary nails of the implants.

All the patients were operated using tibial and femoral implants that included uncemented nails (Scorpio® TS Total Knee Revision System; Stryker $\left.{ }^{\circledR}\right)$.

In all the patients, we evaluated the following parameters:

- component positioning

- nail length

- nail diameter

- medullary canal diameter, measured by means of radiographs

- nail diameter, measured by means of radiographs

- nail positioning in relation to the orientation of the diaphysis

- occurrences of pain in the lower leg resulting from the nail

- occurrences of pain in the thigh resulting from the nail.

All the data relating to implant size were registered during the surgical procedures.

Information on the diameter and length of the nails used was specified in the surgical register and obtained from the medical file (real measurements of the implants). We analyzed the degree of filling of the tibial medullary canal by the nail, using the following method: the diameters of the nail and medullary canal were measured with a ruler on radiographs, and the point chosen for this was the end of the intramedullary nail. Both of these were measured directly from the radiographs, in order to avoid errors in comparing the real value of the nail diameter (not subject to radiographic megnification) with the value of the medullary canal diameter on the radiograph (subject to this effect). The percentage filling of the medullary canal by the nail was then calculated.

The nail positioning was evaluated from radiographs. Positioning that showed abnormalities in the coronal plane (varus and valgus) and sagittal plane (anteroposterior deviation) of the nail in relation to the orientation of the tibial diaphysis was considered to be inadequate.

To analyze the data, the patients were divided into groups according to the following criteria: presence or absence of pain in the thigh and presence or absence of pain in the lower leg (Figure 1).

For the statistical analysis on the data relating to diameter and percentage filling, the $t$ test was used. For the data on nail length and positioning, the $x^{2}$ (chisquare) test was used.

\section{RESULTS}

Thirty-one patients were evaluated, of whom 17 were women and 14 were men (total of 32 knees, given that one male patient underwent bilateral revision arthroplasty), with a mean age of 66.7 years (patients with ages ranging from 45 to 82 years).

After evaluation and follow-up (mean follow-up of 2.6 years), we observed that three patients (three knees) or $9.37 \%$ presented thigh pain and seven patients (seven knees) or $21.87 \%$ presented lower-leg pain, with different intensities. Two patients (two knees) or $6.25 \%$ presented thigh and lower-leg pain simultaneously; and eight patients (eight knees) or $25 \%$ presented diaphyseal pain, independent of the site (Box 1 ).

The group of patients with lower-leg pain presented a mean diameter of the tibial nail of $14.7 \mathrm{~mm}$ (range: 13 to $18 \mathrm{~mm}$ ); the nail length was $80 \mathrm{~mm}$ in $71.42 \%$ and $155 \mathrm{~mm}$ in $28.58 \%$ of the patients; and the mean diameter of the medullary canal was 15.6 $\mathrm{mm}$ (range: 12 to $18 \mathrm{~mm}$ ). The ratio of nail diameter/ mean intramedullary canal diameter was 0.76 . Three patients or $42.8 \%$ presented poor nail alignment.

The group of patients without lower-leg pain presented a mean diameter of the tibial nail of $15.2 \mathrm{~mm}$ (range: 10 to $21 \mathrm{~mm}$ ); the nail length was $80 \mathrm{~mm}$ in $68 \%$ and $155 \mathrm{~mm}$ in $32 \%$ of the patients; and the mean diameter of the medullary canal was $17.7 \mathrm{~mm}$ (range: 13 to $21 \mathrm{~mm}$ ). The ratio of nail diameter/mean intramedullary canal diameter was 0.79 . Five patients or $20.8 \%$ presented poor nail alignment.

The group of patients with thigh pain presented a mean diameter of the femoral nail of $18.3 \mathrm{~mm}$ (range: 14 to $23 \mathrm{~mm}$ ); the nail length was $80 \mathrm{~mm}$ in $66.67 \%$ and $155 \mathrm{~mm}$ in $33.33 \%$ of the patients; and the mean diameter of the medullary canal was $31.0 \mathrm{~mm}$ (range: 21 to $38 \mathrm{~mm}$ ). The ratio of nail diameter/mean in- 


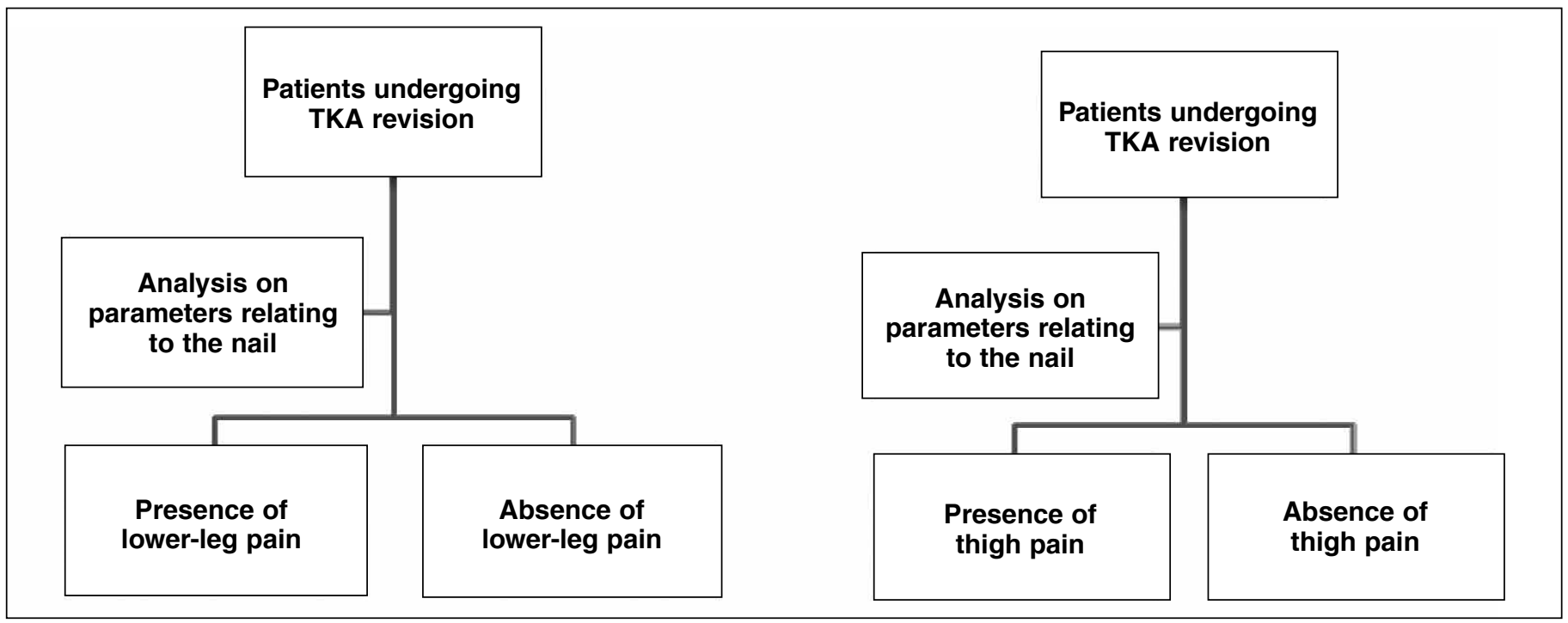

Figure 1 - Study design.

tramedullary canal diameter was 0.75 . None of the patients presented poor nail alignment.

The group of patients without thigh pain presented a mean diameter of the femoral nail of $16.56 \mathrm{~mm}$ (range: 13 to $23 \mathrm{~mm}$ ); the nail length was $80 \mathrm{~mm}$ in $70.37 \%$ and $155 \mathrm{~mm}$ in $29.63 \%$ of the patients; and the mean diameter of the medullary canal was 21.1 $\mathrm{mm}$ (range: 12 to $34 \mathrm{~mm}$ ). The ratio of nail diameter/mean intramedullary canal diameter was 0.79 . Four patients or $14.2 \%$ presented poor nail alignment (Tables 1 and 2).

Box 1 - Prevalence of pain at the tip of the femoral and/or tibial nail after revision arthroplasty on knee prosthesis.

\begin{tabular}{|c|c|}
\hline Thigh pain / Total & $9.37 \%$ \\
\hline Lower-leg pain / Total & $21.87 \%$ \\
\hline Thigh and lower-leg pain / Total & $6.25 \%$ \\
\hline Thigh and/or lower-leg pain / Total & $25.00 \%$ \\
\hline
\end{tabular}

Table 1 - Mean nail diameters and percentage filling of the medullary canal in the groups analyzed.

\begin{tabular}{|c|c|c|c|}
\hline \multicolumn{2}{|c|}{$\begin{array}{l}\text { Mean diameter of the femoral } \\
\text { nail (in millimeters) }\end{array}$} & \multicolumn{2}{|c|}{$\begin{array}{l}\text { Mean diameter of the tibial nail } \\
\text { (in millimeters) }\end{array}$} \\
\hline $\begin{array}{c}\text { Group } 1 \text { - with thigh } \\
\text { pain }\end{array}$ & 18.33 & $\begin{array}{l}\text { Group } 3 \text { - with } \\
\text { Lower-leg pain }\end{array}$ & 14.71 \\
\hline $\begin{array}{l}\text { Group } 2-\text { without } \\
\text { thigh pain }\end{array}$ & 16.56 & $\begin{array}{l}\text { Group } 4 \text { - without } \\
\text { Lower-leg pain }\end{array}$ & 15.20 \\
\hline \multicolumn{2}{|c|}{$\begin{array}{l}\text { Percentage filling of the } \\
\text { femoral canal }\end{array}$} & \multicolumn{2}{|l|}{$\begin{array}{l}\text { Percentage filling of the } \\
\text { Tibial canal }\end{array}$} \\
\hline $\begin{array}{l}\text { Group } 1 \text { - with } \\
\text { thigh pain }\end{array}$ & $75.27 \%$ & $\begin{array}{l}\text { Group } 3-\text { with } \\
\text { Lower-leg pain }\end{array}$ & $76.33 \%$ \\
\hline $\begin{array}{l}\text { Group } 2 \text { - without } \\
\text { thigh pain }\end{array}$ & $79.43 \%$ & $\begin{array}{c}\text { Group } 4 \text { - without lower-leg } \\
\text { pain }\end{array}$ & $79.85 \%$ \\
\hline
\end{tabular}

Table 2 - Frequency of use of nails of lengths $80 \mathrm{~mm}$ and 155 $\mathrm{mm}$ in the groups analyzed.

\begin{tabular}{c|c|c}
\hline Nail length & $\mathbf{8 0} \mathbf{~ M m}$ & $\mathbf{1 5 5} \mathbf{M m}$ \\
\hline Group 1 - with thigh pain & $66.67 \%$ & $33.33 \%$ \\
\hline Group 2 - without thigh pain & $70.37 \%$ & $29.63 \%$ \\
\hline Group 3 - with lower-leg pain & $71.42 \%$ & $28.58 \%$ \\
\hline Group 4 - without lower-leg pain & $68.00 \%$ & $32.00 \%$ \\
\hline
\end{tabular}

\section{DISCUSSION}

Pain at the nail tip after TKA revision is a frequent

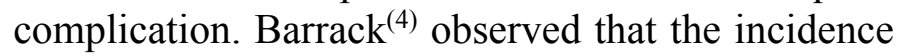
of pain at the nail tip was $11 \%$ in the femur and $14 \%$ in the tibia, while in the present study we observed that $9.37 \%$ of the cases presented pain in the femoral nail and $21.87 \%$ in the tibial nail. With the growing numbers of TKA revisions, this may be a worrying problem and the causes need to be correctly established. The large difference in Young's modulus of elasticity between the nail tip and the bone at their point of contact may be the main factor causing the pain, especially if associated with deficient fixation of the metaphysis ${ }^{(4,7-12)}$. The factors that increase the modulus of elasticity of the nail tip relate to the material used and to increasing nail diameter. The contact pressure between the nail tip and the bone increases in relation to the implant geometry, bone geometry and great degrees of filling of the intramedullary canal by the implant.

The first point for discussion was how to determine whether there is any pain at the nail tip without significant errors. For this, before assessing the patients, we gave them explanations regarding the difference 
between pain in the diaphyseal region of the femur or tibia, called pain at the nail tip, and other possible pains in the knee and hip regions. Furthermore, the physician who made the assessments was the same in all cases, to avoid inter-observer subjectivity. Anamnesis and detailed clinical examination were conducted.

We had imagined that nails of greater diameter would correlate with greater incidence of pain. However, we did not observe any association between the incidence of pain and the diameters of the nails, or between the pain and the ratio of filling of the medullary canal with the nail.

The intramedullary canals of the femur and tibia present progressively smaller diameters going away from the knee, i.e. with a shape resembling a funnel. They are widest in the metaphyseal region and reach a parallel-sided shape bordered by cortical bone in the diaphyseal region. Thus, from a geometrical and biomechanical point of view, a short "press fit" nail presents a greater chance of becoming supported in the metaphyseal-diaphyseal region, thus concentrating the stress and causing a painful area in this region. Theoretically, it would be expected that a longer nail would cause less pain, since its tip would be located in a region where the cortical bone walls were more parallel, with less concentration of the forces. On the other hand, during our follow-up, we did not observe any association between occurrences of pain and the lengths of the femoral and tibial nails.

In relation to inadequate nail positioning (lack of parallelism between the nail and the cortical bone), we again did not observe any association between these parameters and occurrences of complaints of pain. In these cases, a concentration of mechanical stress may form at the point of contact between the nail and cortical bone, which may induce greater incidence of pain. Despite this, we did not observe any statistically significant correlation in any of the parameters evaluated.

Some new types of implant have been developed, with slits at the nail tip in the coronal plane for the femur and the sagittal plane for the tibia, or with slits in both planes ${ }^{(13)}$. These implants tend to diminish the modulus of elasticity of the nail tip and decrease the chance of a painful point of contact, but the benefits have not yet been scientifically proven.

For as long as the causes of thigh and lower-leg pain in patients undergoing TKA revision using nails are not clearly understood, further studies will be needed to try to elucidate the causes. This, together with the development of new materials and changes to prosthesis design, may lead to lower rates for the frequent complaint of diaphyseal pain.

\section{CONCLUSION}

Pain reported in the region of the tip of the femoral or tibial nail is a very common complication after TKA revision, and it affects more than $20 \%$ of the patients. There was no association between the diameter or length of the fixation nail and pain in the region of the nail tip. There was also no association between the ratio of nail diameter/intramedullary canal diameter and pain at the nail tip, or in relation to nail positioning.

\section{REFERENCES}

1. Friedman RJ, Hirst P, Poss R, Kelley K, Sledge CB. Results of revision total knee arthroplasty performed for aseptic loosening. Clin Orthop Relat Res. 1990;(255):235-41.

2. Järvenpää J, Kettunen J, Miettinen H, Kröger H. The clinical outcome of revision knee replacement after unicompartmental knee arthroplasty versus primary total knee arthroplasty: 8-17 years follow-up study of 49 patients. Int Orthop. 2010;34(5):649-53.

3. Conditt MA, Parsley BS, Alexander JW, Doherty SD, Noble PC. The optimal strategy for stable tibial fixation in revision total knee arthroplasty. J Arthroplasty. 2004;19(7 Suppl 2):113-8.

4. Barrack RL, Rorabeck C, Burt M, Sawhney J. Pain at the end of the stem after revision total knee arthroplasty. Clin Orthop Relat Res. 1999;(367):216-25.

5. Peters CL, Erickson J, Kloepper RG, Mohr RA. Revision total knee arthroplasty with modular components inserted with metaphyseal cement and stems without cement. J Arthroplasty. 2005;20(3):302-8.

6. Barrack RL, Jasty M, Bragdon C, Haire T, Harris WH. Thigh pain despite bone ingrowth into uncemented femoral stems. J Bone Joint Surg Br. 1992;74(4):507-10.

7. Petrou G, Gavras M, Diamantopoulos A, Kapetsis T, Kremmydas N, Kouzoupis
A. Uncemented total hip replacements and thigh pain. Arch Orthop Trauma Surg. 1994;113(6):322-6.

8. Skinner HB, Curlin FJ. Decreased pain with lower flexural rigidity of uncemented femoral prostheses. Orthopedics. 1990;13(11):1223-8.

9. Vresilovic EJ, Hozack WJ, Rothman RH. Incidence of thigh pain after uncemented total hip arthroplasty as a function of femoral stem size. J Arthroplasty. 1996;11(3):304-11.

10. Lavernia C, D'Apuzzo M, Hernandez V, Lee D. Thigh pain in primary total hip arthroplasty: the effects of elastic moduli. J Arthroplasty. 2004;19(7 Suppl 2):10-6.

11. Brown TE, Larson B, Shen F, Moskal JT. Thigh pain after cementless total hip arthroplasty: evaluation and management. J Am Acad Orthop Surg. 2002;10(6):385-92

12. Campbell AC, Rorabeck CH, Bourne RB, Chess D, Nott L. Thigh pain after cementless hip arthroplasty. Annoyance or ill omen. J Bone Joint Surg Br. 1992;74(1):63-6.

13. Cameron HU. The role of stems: the long \& short of it. In: Current Concepts of Joint Replacement. Orlando, 2010. p. paper \#107. 